\title{
VIEWPOINT
}

\section{Elf5 - breast cancer's little helper}

\author{
Hayley T Frend and Christine J Watson*
}

\begin{abstract}
A variety of transcription factors has been shown to regulate lineage commitment in the mammary gland and to be associated with different molecular subtypes of breast cancer. E74-like factor 5 (Elf5) has now been identified as a marker of oestrogen receptor status, and high expression correlates with more aggressive basal cancers and resistance to anti-oestrogens. Manipulation of Elf5 transcript levels perturbs the molecular profiles of luminal and basal subtypes, highlighting the possibility that targeting Elf5 could provide a new approach for the treatment of basal cancers.
\end{abstract}

Molecular profiling has resulted in the classification of breast cancer into six distinct subtypes [1,2] that have differential prognoses and optimal treatment regimes. The subgroups with the best prognosis are the luminal $\mathrm{A}$ and luminal B groups, which are distinguished by their expression of oestrogen receptor (ER) alpha. Luminal A and luminal $\mathrm{B}$ are the most commonly diagnosed types, comprising $70 \%$ of breast tumours. Correspondingly, the most widely used treatment for breast cancers is antioestrogen therapy, which is very effective for patients with $\mathrm{ER}^{+}$tumours.

Personalised therapy for breast cancer is a current goal, and characterisation of breast tumour biopsies into particular molecular subtypes with predicable outcomes is essential to achieve this goal. This characterisation requires a better understanding of the signature genes in these subtype profiles and the molecular mechanisms by which they are determined. This will provide insights into tumour initiation and progression and will better guide treatment strategies. Furthermore, many breast tumours recur and about $30 \%$ of patients develop resistance to anti-oestrogen therapy. The mechanism for this resistance is not clear and is currently an important area of research.

*Correspondence: cjw53@cam.ac.uk

Department of Pathology, University of Cambridge, Tennis Court Road, Cambridge CB2 1QP, UK
The transcriptional regulator E74-like factor 5 (Elf5) has previously been associated with regulation of placentation [3] and alveologenesis, the process by which the mammary gland develops milk-producing acinar structures during pregnancy $[4,5]$. In a manuscript from Chris Ormandy's laboratory, published recently in PLoS Biology [6], the authors hypothesised that Elf5 - which is expressed primarily in the $\mathrm{ER}^{-}$progenitor cells in the mouse mammary gland - could have a role in determining the different subtypes of breast cancer. Firstly, they examined Elf5 expression in published datasets and found that expression was highest in the basal and normal-like subtypes and also in normal breast, while expression was low in all other subtypes. Using inducible expression of Elf5 in the ER ${ }^{+}$luminal breast cancer cell lines T47D and MCF7, Elf5 binding sites were determined by chromatin immunoprecipitation-sequencing analysis. This analysis identified 164 target genes including forkhead box protein A1 (FOXA1), RUNX1 and GATA3. Additionally, a panel of mitogenic genes were shown to be repressed by Elf5. This 164-gene signature accurately predicts ER status, suggesting that the poorer prognosis of $E R^{-}$ tumours could be due to Elf5-regulated genes. Importantly, forced Elf5 expression suppresses oestrogen sensitivity indirectly and, while oestrogen can reduce Elf5 expression, this was blunted in tamoxifen-resistant cells. The most striking outcome of this work is that Elf5 can alter the molecular subtype as luminal cells become either basal and Her2+ (MCF7) or normal-like and claudin-low (T47D), while HCC1937 basal cells become normal-like and claudin-low.

This manuscript is a gene expression analysis tour de force. Consequently, there is a substantial amount of data to be digested that will be appreciated particularly by the conoscenti. However, the significance of the paper can be distilled into two main observations. Firstly, the level of Elf5 expression can change the molecular subtype of breast cancer cell lines implicating Elf5 as a critical regulator of subtype. Secondly, Elf5 is a marker of ER ${ }^{-}$cells, suppresses oestrogen activity in luminal cells and overrides the anti-proliferative effects of anti-oestrogens, possibly promoting resistance. These are interesting and important discoveries and raise the possibility that expression of Elf5 could be a marker of future antioestrogen therapy failure in $\mathrm{ER}^{+}$tumours. 
A number of challenging questions arise from this work. Firstly, there is a major difference in terms of molecular signature between the response of T47D and MCF7 cells (both luminal ER ${ }^{+}$) to forced Elf5 expression. Will every $\mathrm{ER}^{+}$luminal breast cancer cell line behave differently to Elf5 overexpression and how can we extrapolate these findings to real ER ${ }^{+}$tumours? Clearly, cell-specific and subtype-specific factors interact with Elf5. What are these interacting factors? FOXA1 has recently been shown to have a similar role to Elf5 in that it can regulate luminal and basal cell plasticity - knockdown of FOXA1 in luminal breast cancer cells results in a basal molecular signature [7]. Since Elf5 regulates FOXA1, which in turn regulates expression of ER $\alpha$ [8], there could be antagonism between Elf5 and FOXA1 for binding to the ER $\alpha$ promoter. This interaction is further complicated by the role of GATA3, which is a marker of the luminal subtypes and is shown in this study to be regulated by Elf5, although it is not a FOXA1 target [8].

Perhaps curious is that the expression of Elf5 is similar in the cancer subtype with the worst prognosis (basal) to that in normal breast. This brings us to the normal developmental role of Elf5 where overexpression in virgin animals induces precocious alveologenesis [9]. The authors suggest that Elf5 establishes the secretory alveolar cell lineage and that Elf5 and FOXA1 provide the key to progenitor cell fate decisions. Recent genetic studies demonstrated that the balance of the $\mathrm{ER}^{+} / \mathrm{Gata} 3$ and $\mathrm{ER}^{-} / \mathrm{pStat} 5$ lineages is determined by the transcriptional repressor Zfp157 [10]. The relationship between Elf5 and Zfp157 has not been determined but raises the question of how expression of Elf5 is regulated. The chromatin immunoprecipitation-sequencing analysis pulled out Stat binding motifs, and Stat5 has been suggested to be a regulator of Elf5 expression [11]. Is there a positive regulatory loop between Stat 5 and Elf5 and/or competition between Elf5 and Stat 5 for target genes?

We are now beginning to understand the mechanisms that regulate the transcriptional profiles of breast cancer subtypes. This should result in better prognostic analyses and the design of targeted therapies for basal and antioestrogen-resistant breast cancers.

\section{Abbreviations}

Elf5, E74-like factor 5; ER, oestrogen receptor; FOXA1, forkhead box protein A1; GATA3, GATA binding protein 3; Her2, heregulin 2; RUNX1, runt-related transcription factor 1 ; Stat, signal transducer and activator of transcription; Zfp157, zinc finger protein 157.
Competing interests

The authors declare that they have no competing interests.

\section{Acknowledgements}

HTF is funded by a Wellcome Trust PhD studentship. Work in CJW's laboratory is funded by MRC and BBSRC.

Published: 27 March 2013

\section{References}

1. Sørlie T, Perou CM, Tibshirani R, Aas T, Geisler S, Johnsen H, Hastie T, Eisen MB, van de Rijn M, Jeffrey SS, Thorsen T, Quist H, Matese JC, Brown PO, Botstein D, Lønning PE, Børresen-Dale AL: Gene expression patterns of breast carcinomas distinguish tumor subclasses with clinical implications. Proc Natl Acad Sci USA 2001, 98:10869-10874.

2. Prat A, Parker JS, Karginova O, Fan C, Livasy C, Herschkowitz J, He X, Perou CM: Phenotypic and molecular characterization of the claudin-low intrinsic subtype of breast cancer. Breast Cancer Res 2010, 12:R68.

3. Donnison M, Beaton A, Davey HW, Broadhurst R, L'Huillier P, Pfeffer PL: Loss of the extraembryonic ectoderm in Elf5 mutants leads to defects in embryonic patterning. Development 2005, 132:2299-2308.

4. Choi YS, Chakrabarti R, Escamilla-Hernandez R, Sinha S: Elf5 conditional knockout mice reveal its role as a master regulator in mammary alveolar development: failure of Stat 5 activation and functional differentiation in the absence of Elf5. Dev Biol 2009, 329:227-241.

5. Watson CJ, Khaled WT: Mammary development in the embryo and adult: a journey of morphogenesis and commitment. Development 2008, 135:995-1003.

6. Kalyuga M, Gallego-Ortega D, Lee HJ, Roden DL, Cowley MJ, Caldon CE, Stone A, Allerdice SL, Valdes-Mora F, Launchbury R, Statham AL, Armstrong N, Alles MC, Young A, Egger A, Au W, Piggin CL, Evans CJ, Ledger A, Brummer T, Oakes SR, Kaplan W, Gee JM, Nicholson RI, Sutherland RL, Swarbrick A, Naylor MJ, Clark SJ, Carroll JS, Ormandy CJ: ELF5 suppresses estrogen sensitivity and underpins the acquisition of antiestrogen resistance in luminal breast cancer. PLOS Biol 2013, 10:e1001461.

7. Bernardo GM, Bebek G, Ginther CL, Sizemore ST, Lozada KL, Miedler JD, Anderson LA, Godwin AK, Abdul-Karim FW, Slamon DJ, Keri RA: FOXA1 represses the molecular phenotype of basal breast cancer cells. Oncogene 2012, 32:554-563.

8. Bernardo GM, Lozada KL, Miedler JD, Harburg G, Hewitt SC, Mosley JD, Godwin AK, Korach KS, Visvader JE, Kaestner KH, Abdul-Karim FW, Montano MM, Keri RA: FOXA1 is an essential determinant of ERa expression and mammary ductal morphogenesis. Development 2010, 137:2045-2054.

9. Oakes SR, Naylor MJ, Asselin-Labat ML, Blazek KD, Gardiner-Garden M, Hilton HN, Kazlauskas M, Pritchard MA, Chodosh LA, Pfeffer PL, Lindeman GJ, Visvader JE, Ormandy CJ:The Ets transcription factor Elf5 specifies mammary alveolar cell fate. Genes Dev 2008, 22:581-586.

10. Oliver CH, Khaled WT, Frend H, Nichols J, Watson CJ: The Stat6-regulated KRAB domain zinc finger protein Zfp157 regulates the balance of lineages in mammary glands and compensates for loss of Gata-3. Genes Dev 2012, 26:1086-1097.

11. Yamaji D, Na R, Feuermann Y, Pechhold S, Chen W, Robinson GW, Hennighausen $L$ : Development of mammary luminal progenitor cells is controlled by the transcription factor STAT5A. Genes Dev 2009, 23:2382-2387.

\section{doi:10.1186/bcr3397}

Cite this article as: Frend HT, Watson CJ: Elf5 - breast cancer's little helper. Breast Cancer Research 2013, 15:307. 